\title{
An ethic of connectedness: enacting moral school leadership through people and programs
}

\section{J. Edward Frick}

Donegal High School, Pennsylvania, USA

\section{William C. Frick}

University of Oklahoma, USA

\begin{abstract}
As educators, we grapple with a myriad of dilemmas and often have difficulty resolving issues that relate to curriculum and instruction, funding, facilities and supervision, to name a few. Depending on the leader(s), a variety of ethics come in to play when making decisions. The ethic of connectedness refers to community building and welfare as central to moral thought and practice (Bradley, 2007). Responsibility to community building and welfare begins in the schools and must be an acculturated practice within the schools so future generations possess the knowledge, skills and dispositions that ensure a connectedness to their society (Marzano et al., 2005; Barth 2006; Collinson et al., 2006). This article will explore the importance of an ethic of connectedness to effective school leadership and the experience of a Pennsylvania school district in nurturing and building a connectedness within the school community.
\end{abstract}

\section{Keywords}

community, community building, ethical decision-making, ethics, school leadership

\section{Introduction}

As educators, we grapple with a myriad of moral problems and ethical dilemmas and often have difficulty resolving issues that relate to curriculum and instruction, funding, facilities and supervision, to name a few. Depending on the leader, a variety of ethical and moral stances or approaches come into play when making decisions. Much of the practical ethics espoused within the field of educational leadership focus on the individual actor as leader based on moral suasion (Greenfield, 1988; Campbell, 2003; Fullan, 2004; Starratt, 2005). This article seeks to broaden and reconceptualize moral leadership as spread over many persons comprising a school community. Just as leadership

\section{Corresponding author:}

J. Edward Frick, Donegal High School, 915 Anderson Ferry Road, Mount Joy, PA I7552, USA.

Email: edward.frick@donegal.kI2.pa.us 
(in terms of expertise and brainpower) is now understood to be distributed (Elmore, 2000; Spilline et al., 2001, 2004, Coldren and Spillane, 2007) within organizational life, moral and ethical leadership must be as well. An 'ethic of connectedness' can serve as a way to conceptualize the process and quality of collective moral leadership.

The ethic of connectedness refers to community building and welfare as central to moral thought and practice (Bradley, 2007). Responsibility for community building and cooperative welfare can begin in different ways and in a variety of situations and locals, but for our purposes, the schools must play a major role. Community building and cooperative welfare must be an acculturated practice within the schools so future generations possess the knowledge, skills and dispositions that ensure a connectedness to their society (Marzano et al., 2005; Barth, 2006; Collinson et al. 2006). This article will explore the importance of an ethic of connectedness for effective school leadership and the experience of a school district in nurturing and building a connectedness within the school community.

Education is replete with dialogue addressing student achievement and performance and how to successfully engage students within the educational context (Marzano et al., 2001, 2005; Marzano, 2006, 2007; Pollock, 2007; Tomlinson and McTighe, 2006). As leaders in the field of education, it is vital to have an understanding of the importance of students being connected to their school and the role that has on achievement (Blum, 2005). Educational leaders deal with ethical decisionmaking on a daily basis and work from a variety of frameworks in this area. Given recent health, educational and political analysis, this article will illustrate the importance of an ethic of connectedness as a framework within educational leadership and how one Pennsylvania school district has applied that ethic within its school community (Blum, 2005; Marzano et al., 2005).

\section{Considering normative ethical frameworks in education}

Moral philosophy provides a backdrop to situate and better understand the distinct theoretical perspectives of ethical and moral leadership within educational administration. There are primarily five ethical themes or standpoints considered in the field of educational leadership. These moral perspectives, typically articulated as theories of duty, guidance for individual ethical decisionmaking, expressions of relational morality, or guidance for establishing moral school environments, comprise the basis from which much of the empirical literature exists. For this particular study, a separate consideration of each of the theoretical standpoints is important because it informs the central aspects of an ethic of connectedness framing this study.

\section{Justice}

A justice perspective, or what has been referred to in the literature and practice within the profession as an 'ethic of justice', is clearly expressed in the work of Strike et al. (1998). This perspective focuses on ethical concepts that constitute the foundational principles of liberal democracies. Taken as a whole, they can be described as a 'civic ethic' where it is believed that all persons irrespective of culture, race or other defining categories possess the capacity for a sense of justice and the ability to conceptualize what is their own good. People have the capacity to critique their notion of justice and the good life and are capable of transcending cultural contexts in order to achieve analytic distance when testing principles such as due process, freedom, equality and the common good.

There is a fundamental tension within the perspective of observing justice. Two broad schools of thought occupy the continued discussion over a civic ethic. One position places the individual person as an independent reality prior to social relationships. Individuals are motivated by self-interest 
and engage in social relations for their own benefit. Social contracts that support societies and governments are essentially individuals agreeing to surrender some liberty in return for amicable relations with others or protection from others' self-interest. The basis for these beliefs appears to have emerged from two competing perspectives of public discussion in Western culture. One view held that everything people have - including political rights and freedoms - originates with God. Another view supposed that God had granted humanity the moral freedom to construct its own societies and that rights and freedoms are the result of social contracts based on human reason and experience. Regardless of the basis for these beliefs, justice is viewed as contractual and legal engineering to bring about harmony between the needs and wants of self-serving individuals (Rawls, 1993).

The second position situates social relationships and society as a prior reality to the individual person. This perspective places the common good of the community as a superior concern over individual self-interest. It is only through living in relation to others that personhood is achieved and moral lessons of communal protection and care are realized. The common good is accomplished by justice that emerges from a community's choice to act and govern fairly for all its members (Sullivan, 1986). Efforts to harmonize the two positions within the justice perspective are evident in the work of Taylor (1994). Sergiovanni and Starratt (1993: 78) express the tension another way by saying 'Whether ... ethical systems are understood as grounded in Natural Law (somewhat the way engineering principles are based on laws of physics ...) or understood as socially constructed guides derived from pragmatic and humanitarian concerns and interests of the civil community is a question long argued by philosophers and social theorists.'

The justice tradition has a longstanding history in the West. Fundamental human rights and the protection of those rights by means of justice are central concepts of postindustrial, liberally democratic, constitutional nation states. But rights and justice do not tell us the whole story about the moral life. Laws and governmental processes can, have been, are, and will be immoral based upon other ways of viewing our collective moral life together. And that collective life can be viewed parochially; but ever increasingly, must be viewed globally. Justice and rights fall short because it views the moral whelm as an institutional and political process whereby a moral minimum is established for relations between people. This perspective tells us little about how we relate to one another as a happy and flourishing community, or doing more than the morally minimal.

\section{Care}

A care perspective, or what has been referred to in the literature and practice within the profession as an 'ethic of care', is clearly expressed in the work of Noddings (1988), Beck (1994) and Gilligan (1982). Interpersonal in nature, this moral perspective focuses on the demands of relationship from a position of unconditional positive regard, or described elsewhere as a deep awareness of 'the other' as persons in community with ourselves as subjects. This position asserts that as human beings (and females perhaps, in particular) we have the capacity to feel deep respect or love for other people and especially people different from ourselves. Our attitudes toward others 'are determined in part by an understanding of who and what they are: in this case, that they are human beings, persons, and that as persons they possess an inner integrity, a self-determination, a capacity for free and spiritual activity that we also sense in ourselves' (Gilkey, 1993). This level of empathy and self-understanding applied to the other can become the foundation for treating persons as ends and not as means, and can, in large part, provide the inner basis of an outward social order.

To be in relationship with others where care, nurturance, respect, compassion and trust are the dominant characteristics is to be fully human. The integrity of human relationship and connection is paramount for this perspective; and consideration of rights, principles and laws are secondary to 
the primacy of beneficence for seeking resolution of moral issues. Acts, dispositions and thinking that are conducive to the well-being of others and a 'commitment to receptive attention and a willingness to respond helpfully to legitimate needs' is the bedrock of moral striving (Noddings, 1996: 265). Rather than restricting the moral domain to considerations of duty and obligation, an ethic of care asks a more foundational question, how shall we live? Care theory 'is relationcentered rather than agent-centered, and it is more concerned with the caring relation than with caring as a virtue' (Noddings, 2002: 2). Both relationship and virtue are acknowledged, but relationship is primary and 'credits the cared-for with a special contribution, one different from reciprocal response as carer' (Noddings, 2002: 2). The cared-for contribute significantly to relational morality, and 'social' virtues are defined situationally within the space of personal interaction.

Close relationships are a central feature of the moral life and constitute another aspect of community that lends an additional vantage to our understanding of practical ethics. Although a focus on the dyadic relationship of care provides insights into the 'I-Thou' existential experience of humankind as a legitimate 'voice' of mutual encounter with the other as a person possessing inner integrity; there appears to be more to the moral story. The emphasis on relation with the singular other can disrupt and warp a 'thoroughgoing consideration of care' (Noddings, 1993: 48) where one's entire web of relations, both as the carer and the cared-for, are robustly considered.

\section{Critique}

A critique perspective, or what has been referred to in the literature and practice within the profession as an 'ethic of critique', is clearly expressed in the work of Foster (1986), Giroux (1992) and Apple (1982). These authors draw their arguments from critical theory and the body of literature derived from the Frankfurt School of philosophers. The critique perspective within educational leadership deals with issues beyond interpersonal relations and serves as a moral posture and examination of larger social and institutional dimensions of human life. Particularly, issues of competing interests, power, the nature and structure of bureaucracy, the influence and force of language, and redress for institutionalized injustice are the focus of critical concern as it relates to the legitimacy of social arrangements.

The disproportionate benefit of some groups over others as a result of political, economic and judicial hegemony are moral concerns that transcend the naïve perspective that societal structures and properties are simply the way things are. Reasoning and acting ethically also entails the inherent paradoxes of leading and managing within an institutional position, on the one hand, and being an activist against practices and procedures that do not support democratic processes, freedom and social justice, on the other.

The moral focus of a critique perspective is concerned with making known and acting upon those circumstances that silence, oppress or discriminate. As Giroux (1992: 7) states:

Leadership poses the issue of [ethical] responsibility as a social relationship in which difference and otherness become articulated into practices that offer resistance to forms of domination and oppression. This raizes the need for a discourse on leadership that prompts a discriminating response to others, one that makes students, for example, attentive to their own implication in particular forms of human suffering and to the oppression of others whose voices demand recognition and support.

A discriminating leadership response to others calls for an elevated critical consciousness about our larger social world, its institutions and the dynamics of power and privilege in framing structures of social reality that can be, if desired, re-envisioned.

Although the critical perspective provides insights into the moral life, especially as "it pertains" to issues of social justice, identity politics and corporatist privatization, there is an aspect inherent 
to theoretically critical ethical standpoints that disallow a clear answer for the problematic social arrangements of our immediate social surround and the larger world. This is especially true when a substantive, robust and publicly enculturated democracy, as a 'powerful script for human freedom' (Giroux, 1992: 37) is employed without specific and workable remedies for the claimed reenvisioning of possibilities through struggle.

\section{Community}

A community perspective, or what has been referred to in the literature and practice within the profession as an 'ethic of community', is clearly expressed in the work of Furman (2003a, 2003b, 2004) and Bellah et al. (1985). According to this viewpoint, moral choices are best made in communitarian settings rather than a traditional focus on the experiences internal to an individual agent. Moving away from the Western notion of individual as leader and moral agent, communitybuilding and communities of practice are emphasized. Community is not defined as an entity but rather an ongoing set of processes that include communication, dialog and collaboration. This position purports that being and acting ethically cannot be achieved without collective commitment to the constructive methods of communal process. The community rather than the individual person is the moral agent and educational leaders are obliged to practice and also engender communal processual skills in others taking part in the work of schools. The term 'processual' is unusual, likely because it is a shift in ontological perspective regarding community. Community, within this tradition, is not necessarily a thing ('tangible entity') but rather a 'sense' achieved by 'ongoing processes of communication, dialogue, and collaboration and not on a set of discrete indicators such as 'shared values...' (Furman, 2002: 285). Community is not viewed as a measured product or entity, but rather a continuous, ongoing process where moral weight is given to inspiring commitment to courses of interpersonal exchange over an end product or something tangible.

A commitment to the processes of community, continuous and recursive, that focus on interpersonal and group awareness, respectful listening, empathetic knowing and understanding of others, effective communication, partnering and working together, supporting and encouraging dialog in open and equal forums, is the foundational value to be internalized and acted upon. The practice of community is prior and foundational to the moral aims and purposes of schooling which include social justice, enactment of democracy and learning for all children.

A communitarian understanding of our collective life together provides a powerful insight about the moral life. What is ethical is not so much what the individual person does in relationship to others, but how the collective responds to environmental and membership needs where Western notions of atomistic individualism, celebrated autonomy, and Hobbesian self-interest give way to moral considerations consisting of egalitarian sentiments, the deep-seated human drive toward living in community with others, and by design, our collective attunement to one another through an awareness of our common humanity. Although powerful sentiments, this perspective is incomplete. How can we live our lives together with no clear sense of personal moral culpability? Communities, no matter how expertly or naturally they are constructed, can avoid the moral weight of the actions of the perpetrator and the suffering of the victim. Not to acknowledge this moral weight would be, in our Western worldview, immoral!

\section{Profession}

A profession perspective, or what has been referred to in literature and practice within educational administration and leadership as an 'ethic of the profession', is clearly expressed in the work of 
Shapiro and Stefkovich (2001, 2005), Stefkovich and O'Brien (2004) and Stefkovich (2006). This perspective argues for an ethical paradigm that considers the 'moral aspects unique to the profession' of education and educational leadership in particular (Shapiro and Stefkovich, 2005: 18). The ethic of the profession considers the ethical frameworks of justice, care, and critique not as totally distinct, incommensurable moral reasoning, but as complementary - a 'tapestry of ethical perspectives that encourages ... rich human response to ... many uncertain ethical situations' (Starratt, 1994: 57). The ethic of the profession, although informed by other moral theory, is distinct unto itself as a framework to guide and inform educational leadership as a practical and moral activity.

The ethic of the profession indicates that a disparity often exists between professional codes meant to inform decision-making and conduct and the personal moral values of administrators that guide their judgment and behavior. An attempt to integrate professional and personal codes of ethics can lead to moral dissonance, or a 'clashing of codes'. In responding to this inevitable discord, the ethic of the profession is grounded in a reasoned consideration of the educational shibboleth 'the best interests of the student' (Walker, 1998).

The student's best interests are the focal point of the ethic of the profession. A model for determining the best interests of the student consists of a robust focus on the essential nature of individual rights, the duty of responsibility to others for a common interest, and respect as mutual acknowledgement of the other as having worth, value, and dignity unto themselves (Stefkovich and O'Brien, 2004; Stefkovich, 2006). The ethic of the profession, and more precisely the best interests of the student model (Stefkovich and O'Brien, 2004; Stefkovich, 2006), has been applied primarily to court decisions from case law pertaining to K-12 education. This application of theory to vignette serves as a helpful pedagogical tool for assisting aspiring and practicing educational leaders to reflect on their decision-making and to understand how professional choices are informed by one's moral reasoning and deliberation, personal values and beliefs and adherence to ethical principles.

A professional ethic for education, implicating those who are cultural workers at any and all institutional levels who are focused on developing and imparting tools to the next generation and beyond, has been viewed as a redundancy (Green, 1987). Professions are defined by the logic of their definitional relationships and goals to a larger public. By sheer virtue of a profession's internal character and structure, normative qualities emerge within it that either include or exclude those from practice. In addition, the very meaning of the maxim, 'the best interests of the student', appears to be varied and indeterminable based upon the multiplicity of circumstance and context.

\section{Virtue}

In addition to the five ethical themes considered in the field of educational leadership, there exists a literature that speaks directly to aretaic judgment of character. These works articulate specific traits and dispositions necessary to think and act morally as an educational leader. Starratt (2004) suggests that becoming a moral school leader requires the development of traits of responsibility, authenticity and presence. Begley (2005), on the other hand, identifies the motivations and dispositions of reflective self-honesty, relational sensitivity and dialogical openness as indispensable qualities of character that are necessary to lead in democratic yet diverse school communities.

Virtue is an important moral insight drawing back to the time of Aristotle's (1989) Nicomachean Ethics, 334-323 BCE, it is not necessarily what you do, it is who you are. Good deeds flow from good character formed through habit, and this basic moral premise finds its relevance in the arena of school leadership. A strict ethics of character is limited though - it does not tell us how to act. Character must be complemented with action. What might be more suitable for this tradition? Possibly a complex understanding of what practical wisdom entails in order to educate and lead for the good - knowing that both characterological disposition and action are required in order to lead morally. 
What do we take to be important in relation to one another? None of the aforementioned ethics either separately or together say enough about the purposes and processes associated with a moral, democratic community in schools (Furman and Starratt, 2002). It is from this assertion that the ethic of connectedness emerges. Our assertion rests with the claims of others within educational leadership. Rudy Crew (2007), former superintendent of Miami-Dade County Public Schools (the fourth largest school system in the USA), in his recently published book, Only Connect, The Way to Save Our Schools, argues for, among many things, the nuanced thought required to bridge gaps, create consensus and find equitable solutions to pressing educational issues. Schools can and should connect us as persons, communities and cultures if we can get morally smart. This theme of connectedness is expressed eloquently by Wagner (2001), who provides a practical theory of action for school leaders for positive change. Collaborative relationships among adults are the key to the dilemma of school reinvention. For leaders, it is not about 'selling' an idea, program or reform model by 'getting buy-in' but rather about engendering ownership and commitment for improved student outcomes. Collective ownership and commitment goes to the level of moral purpose, and the 'biggest challenge for educational leaders is to nurture engagement and commitment rooted in community' (Wagner, 2001: 385).

\section{Supporting literature for an ethic of connectedness}

Connectedness carries with it a broad application. Bradley (2007) discusses connectedness in the context of our relatedness to others. His expression of connectedness as moral and ethical resonates with our basic common humanity. He (2007: 342-343) says:

Because our interconnectedness is growing, it is imperative that our politics should reflect it. Whether the issue concerns America's role in the world or the role of politics in America, our world asks us to care about our neighbors and our planet. Looking beyond the barriers that separate us, we see that all human beings possess common yearnings for family, love, freedom, respect, and fulfillment ... The good news is that practical solutions exist for many of our problems if we act not only in our own self-interest but also in the interest of the whole - interests that, in the long run, coincide with our own.

Although coming from a political perspective, Bradley's ideas on connectedness relate to the problems facing educational leaders and clearly support the moral purpose of schooling in serving the best interests of students.

Noddings (2002) brings this point into the realm of education by suggesting that learning to care for oneself is connected to learning to care for others and that schools can encourage this learning by providing a climate of care and trust. Collinson et al. (2006) echoes this sentiment by emphasizing the importance of building positive and supportive relationships in the school community. School leaders that emphasize outreach, culture and relationships will positively impact student achievement and meet the demands of educating the whole child (Marzano et al. 2005).

The largest body of work supporting an ethic of connectedness comes from the work of Robert Blum of John Hopkins University, who spearheaded the work of an interdisciplinary group of education and health leaders that convened to examine specific steps for improving connections with students (Blum, 2005). Other groups included in this process were the Centers for Disease Control and Prevention's Division of Adolescent School Health, The Johnson Foundation and the Center for Adolescent Health and Development at the University of Minnesota. From this work a clear definition of school connection was offered and insights and strategies were presented that would increase the likelihood of connectedness within a school context. 
According to Blum and Libbey (2004) school connection is the belief by students that adults in school care about their learning as well as about them as individuals. The critical elements needed for students to experience this level of connectedness include: (1) high academic expectations and rigor coupled with support for learning; (2) positive adult-student relationships; and (3) safety: both physical and emotional. If developed within a school setting, connectedness would positively impact a variety of accountability measures like: (1) academic performance; (2) absenteeism; (3) school completion rates; and (4) severe discipline infractions (Goodenow, 1993). Croninger and Lee (2001) demonstrate through their study of teacher-supported at-risk students that increased student connection leads to: (1) enhanced educational motivation; (2) stronger classroom engagement; and (3) improved school attendance thus leading to an increase in academic achievement. It is clear from the aforementioned findings, and our own moral intuition and practical sense-making, that school connectedness needs to be a priority for school leaders, but how can schools encourage this ethic?

A study panel from the National Research Council and Institute of Medicine (2004) provided educators with six strategies that would increase connectedness within a school setting: (1) implementing high standards and expectations while providing academic support to all students; (2) applying fair and consistent disciplinary policies that are collectively agreed upon and fairly enforced; (3) creating trusting relationships among students, teachers, staff, administrators and families; (4) hiring and supporting capable teachers skilled in their respective disciplines, teaching techniques, and classroom management to meet each learners needs while bringing relevancy to content; (5) fostering high parent/family expectations for school performance and school completion; and (6) ensuring that every student feels close to at least one supportive adult at school. These suggestions are reinforced in a practical sense by Wolk (2007: 650) when he states:

Passive schooling creates passive people. If we want people to think, learn, and care about the many dimensions of life, if we want neighbors who accept the responsibility of tending to the world and working to make it a better place, then we need school and curricula that are actually about life and the world ... either we make our schools into vibrant workshops for personal, social, and global transformation, or we must own up to our complicity in perpetuating a superficial, unthinking, and unjust world.

\section{An ethic in practice}

Although connectedness appears in political, health, and educational research and analyses, the underlying ethic remains consistent in that community, welfare and caring are essential to progress. This progress can and must be forged at different levels - globally, internationally, culturally, institutionally and locally - and mass public schooling plays a crucial role. In serving the best interests of students, schools must therefore embrace and engrain within their cultures this ethic of connectedness. The following will outline one school district's effort to do just that. A description of the district and community will be offered followed by the action research practices implemented to support a connectedness ethic within the school community.

\section{Schooling context and method}

Mountain School District is located in northwestern High County and comprises four communities - Rockville, Windytown, Snowcap Township and about one-quarter of Boulderton Township. The communities have a small-town atmosphere each with their own distinct characteristics. The school district demographically maintains a relatively homogenous client base $(93 \%$ White, 2\% Black, 4\% Hispanic and 1\% Asian). Although these towns have many positive 
attributes, the one major issue for the district is a relatively small business and industry base located within the communities. Although Mountain is classified as a rural school district, it continues to increase in population through the growth of housing developments in all three of the communities making up the school district.

Education in the Mountain School District, even with the lack of commerce, has been wholeheartedly supported by local residential property taxation and continues to utilize a variety of academic, co-curricular and extracurricular programs to provide students with a holistic educational experience. The district has three elementary schools, a middle-school and a high school. The schools themselves in many respects are the center of community culture. Many community members turn out for performing arts activities, athletic events and even graduation. This emphasis on community, as well as the holistic development of each student is evident in the educational philosophy espoused by the district:

Our charge is to (1) build fundamental skills, (2) communicate knowledge, and (3) help the individual child take his/her next step in development and adjustment. We will strive to develop each learner as a productive citizen who thoughtfully meets personal, community, and global challenges. (Mountain School District Handbook, 2007: 2)

From this vision and the six strategies proposed by the National Research Council and Institute of Medicine (2004) emerge the practices and programs supporting connectedness in Mountain School District.

Employing practical action research strategies (Mills, 2000) focused on addressing a specific local problem and resulting in an action plan to address the problem, administrator and teacher ad hoc committees at Mountain School District identified a problem and consequent research questions, collected, analyzed and interpreted climate surveys, exit interviews, longitudinal discipline records and academic records. Administrators and lead teachers at each building collaborated on plans of action based on the data collected and developed an action plan and policy. These action plans and proposed policy were then discussed and finalized at the district level. Results of action strategies, which continue to be reviewed and evaluated, serve not only to address Mountain's local concerns and challenges, but to inform larger issues (Fraenkel and Wallen, 2003), namely, the practical implications and manifestations of connectedness as ethical/moral work in schools. The narrative presented here serves as the findings of an action research methodology.

\section{Findings}

Mountain has focused extensively on curriculum enhancement and academic support for students. Curriculum revision has taken place to address standards and benchmarks as well as provide for relevancy for the student population and demographics. A focus on fostering a desire to learn, as well as promoting social responsibility are key components of a holistic education at Mountain. Coinciding with this, Mountain has maintained and revised its efforts in supporting student's academically. Mountain's secondary schools utilize an enrichment period to provide academic support for students on a daily basis. An enrichment period is a forty-minute period at the conclusion of each school day for the purposes of student academic and social support. Students either voluntarily or through teacher assignment attend the enrichment period to receive personalized attention regarding a particular content area. This has proven to be a positive influence in fostering academic support, as well as giving faculty and staff an opportunity to demonstrate care and commitment in an effort to build connectedness in each building and throughout the district. 
Mountain has established fair and consistent policy and enforcement of discipline. The current discipline structure has three components: (1) academic; (2) counseling; and (3) community service. This structure provides each student with a safe study location and assistance with academics, counseling to understand the cause of the behavior, and service learning to demonstrate to the student both his/her role in the community and self-worth as a person. Follow-up on each student takes place along with parental contact to convey student progress in both behavior and academics. This effort in the area of discipline addresses the aforementioned critical areas needed for students to feel connected to their school: (1) support for learning; (2) developing positive adult-student relationships; and (3) safety: both physical and emotional.

Mountain employs a rigorous hiring process that identifies not only skilled teachers in pedagogy and content but teachers that have a positive outlook on children.

Ultimately, the district looks for and professionally develops supportive teachers that take an interest in the lives of their students and have a willingness to work outside the context of their classrooms. Bradley (2007: 107) echoes this sentiment when he states:

In the new story regarding education, teachers know the names of all their students and form collaborative relationships with parents - relationships that might be as simple as regular phone contact or as complex as internet monitoring of each student's performance against a set of criteria measuring skills, attitude, and overall progress.

The district understands that its success or failure rests on the ability to hire effective professional educators.

Fostering high parent and family expectations for school performance and school completion is also an area of focus at Mountain. This belief is tied into aspects of programs throughout the district. The alternative education program at Mountain utilizes a parent contract which outlines the expectations of parents to support their child through academic support, volunteer participation in the program activities, behavioral support and regular involvement in parent, student and teacher meetings. Mountain also utilizes an academic and behavior contract within the regular education setting. This contract serves as a means of reestablishing schooling expectations with the student and his/her family. The establishment of such a contract requires a formal meeting with the family, student, teacher(s) and administration. The incorporation of these contracts within the educational setting has led to higher expectations for performance, improved success of the students under them, and a greater connection between stakeholders in the school community.

In an effort to support connectedness and ensure that every student feels close to one supportive adult, Mountain has a well-established district-wide mentoring program. This program brings together community members and students in an effort to provide nurturing, remediation and a sense of safety within the school environment. It gives the student a platform to view and question real-world issues and discuss them with an adult in a one-on-one setting. The mentors are established at the elementary level and continue with the student through graduation or until the student leaves the district. Wolk (2007: 657) applauds this effort when he states: 'An aim our schools should embrace is to help our children articulate the meanings of their lives.'

With the help of supportive and caring community members, Mountain has taken steps to do just that. Results of exit interviews and student climate surveys have consistently demonstrated the positive impact of Mountain's programs and the proliferation of an ethic of connectedness.

In order for the aforementioned programs to be successful, Mountain has worked extensively to create trusting relationships among students, teachers, staff, administrators and families. The following 
excerpts provided by an administrator at Mountain clearly illustrate the establishment of a trusting relationship in the school community. The first excerpt was taken from a parent email, followed by a written expression from a faculty member and finally a written expression from a student:

Another student was over at our house last evening and she and my son were having conversations about their experiences and observations of Mountain High School. It was so interesting to listen in they feel you have such a tremendous impact on the quality of life here and that the general consensus of students is a respect for you and feelings that you are fair. You truly work at learning to know students and connecting with them on their level. You help to bridge the gap between administration and student body, but still maintain that separation. I believe, with the students as well as the staff, you take those few extra moments to listen, to be fair and to be affirmative. It is not so much the outcome as it is the process. And even when you raise your voice several decibels, I believe most students understand that it is warranted. It takes work, patience, wisdom and commitment - so at least from my family and many more - thank you!

The following was written by a faculty member to a school administrator in the spring of 2006 :

Before I leave for the summer I wanted to thank you for helping to make my year at Mountain and my first year of teaching a positive experience. Right from the start you were there, popping into my class to make sure I was doing okay. I appreciate you taking the time to let me voice frustrations and to answer my questions about how to deal with situations or students. Your continued expressions of appreciation to the faculty meant a lot to me. Perhaps the biggest thing I appreciated about you was your approachability. I knew I could stop to ask advice anytime without fear of being looked down upon. That helped boost my confidence as a teacher and allow me to grow. Thank you so much.

The following was written by a 2006 Mountain graduate regarding a building-level administrator:

First of all, he circulates in the hallways making himself visible and available to students where they are, on their own turf, rather than remaining behind closed doors in his office. He tries to get personal and find students interests so that he can get to know them better and he always tries to attend our extra curricular activities whenever he has a spare moment. It may not seem like much, but students do take notice and definitely take pride in seeing [an administrator] cheering them on at the top of his lungs, and supporting them in all of their various involvements. Additionally, students understand that ultimately his job is to discipline those who misbehave and wreak havoc in school. The difference though, is that no matter the status of the person or the status of the parents of the person, he is fair. Whether it is the kids who have trouble at home and bring it to school, or the star athlete, he treats everyone fairly. One thing that bothers students is to be treated all the same without taking into account past history, willingness of the person to accept responsibility, severity of the discipline infraction, and so on. Finally, he has made an impact on my life because he continues, even as I have graduated this past year, to keep in contact and e-mail me. No matter if it is just to discuss the latest professional hockey game, to check up on me, or even to ask if there is anything I need, really speaks volumes to the type of person he is. I can only imagine how hard it is for him to discipline and yet maintain respect from students, which he has accomplished. From my perspective, I am able to see the number of students that look up to him as a role model.

Without a doubt, an ethic of connectedness increasingly permeates the district and is evident in not only its programs but also its people. 


\section{Conclusions}

There are several implications for educational leaders when focusing on establishing an ethic of connectedness. District leaders need to be advocates for programs and approaches that create positive and purposeful peer support and peer norms as well as, engage in evaluating new and existing curricular approaches, staff and administrator training, and various instructional structures in an effort to enhance a sense of connectedness in the school community. Holistically, schools need to teach students about themselves, foster a love of learning in students, be characterized by care and empathy, and teach social responsibility (Wolk, 2007). This is indeed a tall order for schools not traditionally established to promote such activity or are seeking to address the need for such activity in thoughtful ways (Purpel, 1989). However, by helping children become connected to their school and community, we give them the skills, civic courage and boldness to envision a better world. Taking a broader stance, if we want better communities both locally and globally, then we must help children to imagine a better world so we can act together through a sense of connectedness to make that world a reality (Wolk, 2007).

Educational leaders carry a moral obligation to serve the best interests of students (Fullan, 2004; Stefkovich and Begley, 2007). An illustration of this belief is provided by Bradley (2007: 167) when he explains the viewpoint of a young principal regarding her commitment to education:

Life makes most sense to me when I am able to see and feel how much we are all dependent upon and tied to one another. When I can see this, the future isn't just my personal future, or families' future, but humanity's future ... Those of us who invest in schools are investing in children but by doing so we're investing in ourselves and in the idea that we can live now and forever in each other.

It is evident that moral purpose and connectedness are linked in principle and practice. The leadership of Mountain School District has been mindful that ethical decision-making needs to be reflective while considering a variety of moral frameworks. As evidenced from the aforementioned practices, Mountain has maintained, and continues to hone, its programs, practices and curriculum to promote connectedness. An understanding that the responsibility of leaders in education is to challenge the educational status quo and create a context that is both personally and socially transformative, serves as a focal point for Mountain's leadership team and an example for other districts to consider in their own work with children and youth.

Through applied research practices, Mountain School District continues to identify improvement areas and pursue informed areas of action. The ideas and practices presented in this research, based on Mountain's demographics and community context, can serve to inform and encourage future research about nurturing an ethic of connectedness. In particular, future investigations could focus on the challenges that larger, metropolitan school systems face when striving for a collective ethic of connectedness.

\section{References}

Apple M (1982) Education and Power. Boston: Routledge Kegan Paul.

Aristotle (1989) Nicomachean ethics. Trans. M, Ostwald. New York: Macmillan Publishing Company.

Barth R (2006) Improving relationships within the schoolhouse. Educational Leadership, 63(6): 8-13.

Beck LG (1994) Reclaiming Educational Administration as a Caring Profession. New York: Teachers College Press.

Begley PT (2005) Ethics Matters: New Expectations for Democratic Educational Leadership in a Global Community. University Park, PA: Rock Ethics Institute. 
Bellah R, Madsen R, Sullivan W, Swidler A, and Tipton S (1985) Habits of the Heart: Individualism and Commitment in American Life. Berkley, CA: University of California Press.

Blum R (2005) A case for school connectedness. Educational Leadership 62(7): 16-20.

Blum R, Libbey HP (2004) Executive summary. Journal of School Health 74(7): 231-232.

Bradley B (2007) The New American Story. New York: Random House.

Campbell E (2003) Let right be done: trying to put ethical standards into practice. In: PT Begley, O Johansson (eds) The Ethical Dimensions of School Leadership. Amsterdam: Kluwer Publishers, 107-125.

Coldren AF, Spillane JP (2007) Making connections to teaching practice: the role of boundary practices in instructional leadership. Educational Policy 21(2): 369-396.

Collinson V, Cook TF, and Conley S (2006) Organizational learning in schools and school systems: Improving learning, teaching, and leading. Theory Into Practice 45(2): 107-116.

Crew R (2007) Only Connect: The Way to Save Our Schools. New York: Farrar, Straus and Giroux.

Croninger RG, Lee VE (2001) Social capital and dropping out of high schools: benefits to at-risk students of teachers' support and guidance. Teachers College Record 103(4): 548-581.

Elmore RF (2000) Building a New Structure for School Leadership. Washington, DC: The Albert Shanker Institute.

Foster W (1986) Paradigms and Promises: New Approaches to Educational Administration. Buffalo, NY: Prometheus Books.

Fraenkel JR, Wallen NE (2003) How to Design and Evaluate Research in Education, 5th edn. New York: McGraw-Hill.

Fullan M (2004) The Moral Imperative of School Leadership. Thousand Oaks, CA: Corwin Press.

Furman GC (2002) School as Community: from Promise to Practice. Albany, NY: SUNY Press.

Furman, GC (2003a) The 2002 UCEA presidential address: toward a 'new' scholarship of educational leadership. UCEA Review 45(1): 1-6.

Furman GC (2003b) Moral leadership and the ethic of community. Values and Ethics in Educational Administration 2(1): 1-7.

Furman GC (2004) The ethic of community. Journal of Educational Administration 42: 215-235.

Furman GC, Starratt RJ (2002) Leadership for democratic community in schools. In: J Murphy (ed.) The Educational Leadership Challenge: Redefining Leadership for the 21st Century. Chicago, IL: National Society for the Study of Education, 105-133.

Gilkey L (1993) Nature, Reality, and the Sacred. Minneapolis, MN: Augsburg-Fortress Press.

Gilligan C (1982) In a Different Voice. Cambridge, MA: Harvard University Press.

Giroux HA (1992) Border Crossings: Cultural Workers and the Politics of Education. New York: Routledge.

Goodenow C (1993) Classroom belonging among early adolescent students: relationships to motivation and achievement. Journal of Early Adolescence 13(1): 21-43.

Green TE (1987) The conscience of leadership. In: L Shieve, M Schoenheit (eds) Leadership: Examining the Elusive. 1987 Yearbook. Alexandria, VA: Association for Supervision and Curriculum Development.

Greenfield TB (1988) The decline and fall of science in educational administration. In: DE Griffiths, RT Stout, and PB Forsyth (eds) Leaders for America's Schools. Berkley, CA: McCutchan, 131-159.

Marzano RJ (2006) Classroom Assessment and Grading That Work. Alexandria, VA: Association for Supervizion and Curriculum Development.

Marzano RJ (2007) The Art and Science of Teaching. Alexandria, VA: Association for Supervision and Curriculum Development.

Marzano RJ, McNulty BA, and Waters T (2005) School Leadership That Works: From Research to Results. Aurora, CO: Mid-continent Research for Education and Learning.

Marzano RJ, Pickering DJ, and Pollock JE (2001) Classroom Instruction That Works: Research Based Strategies for Increasing Student Achievement. Alexandria, VA: Association for Supervision and Curriculum Development. 
Mills GE (2000) Action Research: A Guide for the Teacher Researcher. Upper Saddle River, NJ: Merrill. Mountain School District (2007) Mountain School District Handbook. Mountain, PA: Mountain School District.

National Research Council and Institute of Medicine (2004) Engaging Schools: Fostering High School Students 'Motivation to Learn. Board on Children, Youth, and Families, Division of Behavioral and Social Sciences and Education. Washington, DC: The National Academies Press.

Noddings N (1988) An ethic of caring and its implications for instructional arrangements. American Journal of Education 96(2): 215-230.

Noddings N (1993) Caring: a feminist perspective. In: KA Strike, PL Ternasky (eds) Ethics for Professionals in Education. New York: Teachers College Press, 43-53.

Noddings N (1996) On community. Educational Theory 46(3): 245-267.

Noddings N (2002) Educating Moral People: A Caring Alternative to Character Education. New York: Teacher College Press.

Pollock J (2007) Improving Student Learning One Teacher at a Time. Alexandria, VA: Association for Supervision and Curriculum Development.

Purpel DE (1989) The Moral and Spiritual Crisis in Education. New York: Gergin Garvey.

Rawls J (1993) Political Liberalism. New York: Columbia University Press.

Sergiovanni TJ, Starratt RJ (1993) Supervision: A Redefinition. New York: McGraw-Hill.

Shapiro JP, Stefkovich JA (2001) Ethical Leadership and Decision Making in Education: Applying Theoretical Perspectives to Complex Dilemmas. Mahwah, NJ: Lawrence Erlbaum Associates.

Shapiro JP, Stefkovich JA (2005) Ethical Leadership and Decision Making on Education: Applying Theoretical Perspectives to Complex Dilemmas, 2nd edn. Mahwah, NJ: Lawrence Erlbaum Associates.

Spilline JP, Halverson R, and Diamond JB (2001) Investigating school leadership practice: a distributed perspective. Educational Researcher 30(3): 23-28.

Spilline JP, Halverson R, and Diamond JB (2004) Towards a theory of leadership practice: a distributed perspective. Journal of Curriculum Studies 36(1): 3-34.

Starratt RJ (1994) Building an Ethical School: A Practical Response to Moral Crisis in Schools. London: Falmer Press.

Starratt RJ (2004) Ethical Leadership. San Francisco, CA: Jossey-Bass.

Starratt RJ (2005) Responsible leadership. The Educational Forum 69(2): 124-133.

Stefkovich J (2006) Best Interests of the Student: Applying Ethical Constructs to Legal Cases in Education. Mahwah, NJ: Lawrence Erlbaum Associates.

Stefkovich JA, Begley PT (2007) Ethical school leadership: defining the best interests of students. Educational Management Administration \& leadership 35(2): 205-224.

Stefkovich JA, O'Brien GM (2004) Best interests of the student: an ethical model. Journal of Educational Administration 42(2): 197-214.

Strike KA, Haller EJ, and Soltis JF (1998) The Ethics of School Administration, 2nd edn. New York: Teachers College Press.

Sullivan WM (1986) Reconstructing Public Philosophy. Berkley, CA: University of California Press.

Taylor C (1994) The politics of recognition. In: A Gutmann (ed.) Multiculturalism.) Princeton, NJ: Princeton University Press, 25-73.

Tomlinson CA, McTighe J (2006) Integrating Differentiated Instruction and Understanding by Design. Alexandria, VA: Association for Supervision and Curriculum Development.

Wagner T (2001) Leadership for learning: an action theory of school change. Phi Delta Kappan 82(5): 378-383. Walker KD (1998) Jurisprudential and ethical perspectives on 'the best interests of children'. Interchange 29(3): 283-304.

Wolk S (2007) Why go to school? Phi Delta Kappan 88: 648-658. 